coloproctology $2017 \cdot 39: 341-343$ https://doi.org/10.1007/s00053-017-0193-9

Published online: 8 September 2017

(c) Springer Medizin Verlag GmbH 2017

CrossMark

\author{
H. Rosen ' J. Hebenstreit ${ }^{2}$ G. Möslein ${ }^{3} \cdot$ W. Kneist ${ }^{4}$ G. Liebig-Hörl $~ \cdot$ A. Fürst ${ }^{1,5}$ \\ 'Chair "Surgical Oncology", Sigmund Freud Medical School, Vienna, Austria \\ ${ }^{2}$ Department of Surgery, Barmherzige Brüder, Graz, Austria \\ ${ }^{3}$ Center for Hereditary Tumors, HELIOSUniversity Hospital Wuppertal, Wuppertal, Germany \\ ${ }^{4}$ Department of General, Visceral and Transplant Surgery, University Medical Centre of the Johannes \\ Gutenberg University, Mainz, Germany \\ ${ }^{5}$ Klinik für Allgemein-, Viszeral-, und Thorachirurgie, Adipositasmedizin, Caritas-KH St. Josef, Regensburg, \\ Germany
}

\title{
Prophylactic transanal irrigation for low anterior resection syndrome following rectal resection
}

\section{Study protocol of a randomized controlled multicenter trial}

and-finally-anal incontinence of various degrees of severity [1-3].

More recently, LARS and its major negative impact on quality of life (QoL) have gained increasing attention in the medical literature. Today, it is widely accepted that some or all of the aforementioned functional problems will be experienced by up to $80 \%$ of all patients after anterior rectal resection.

Although it was the general opinion that most of these functional impairments will significantly improve within 6-12 months, more recently published long-term data show persistence of LARS in about $50 \%$ of patients even up to more than 10 years after their primary surgery $[4,5]$.

Loss of the reservoir function of the removed rectal ampulla and changes in the colonic motility following mobilization of the left hemicolon have been associated with most of the observed functional changes $[1,6]$. Low rectal volume and low maximal rectal capacity as well as deteriorated anal sphincter function have been considered the major mechanisms leading to LARS and are additionally negatively influenced by neoadjuvant radiotherapy [4].
Although various surgical attempts have been made to approach this problem by formation of a neo-reservoir ( $\mathrm{J}$ pouch, coloplasty, Baker anastomosis), it is accepted that this does not lead to a complete resolution of all LARSassociated problems [7]. Even after successful construction of a "neoreservoir" by means of a colonic J-pouch, up to six defecation episodes per day have been observed after more than 12 months' follow-up. Furthermore, it should be noted that in a certain number of patients only a straight coloanal anastomosis will be technically feasible owing to anatomic limitations [7].

In addition to this, more recent research of colorectal physiology has revealed that removal of the sigmoid and rectum has a major impact on colonic motility leading to an elimination of the so-called rectal motor complex, which is regarded as a mechanism that is able to slow down ("brake") the transport of bowel content [8].

Owing to the significant negative impact of LARS on QoL, increasing attention has been placed on the management of this problem. Although a more structured classification of the degree of this tent ("clustering"), emptying difficulties, 
disorder by a validated scoring system has been achieved [9], successful treatment has been limited to date.

Dietary approaches including a fiberrich diet and constipating agents as well as pelvic floor muscle training are still regarded as the first-line therapy although scientific evidence of their effect in LARS is lacking and their efficacy in this special subset of patients must be questioned [10, 11].

The introduction of sacral nerve stimulation (SNS) as an effective treatment for functional pelvic floor problems has led to its application in some patients with LARS. Although the success of this therapy has been described in single-center publications and case reports, the high price of the device and the lack of scientific evidence prevent it from being recommended for wider use in patients with LARS [12].

Transanal irrigation (TAI) was described as an effective approach for functional problems following rectal resection as early as 1989 [13]; however, TAI failed to get broader attention in the surgical community and it was only until the new millennium that different European study groups "reinvented" this treatment for severe LARS in the followup of patients after rectal resection [10, 11, 14].

These publications show nicely that a regular wash-out of the colon will lead to a marked reduction in defecation episodes, as well as the possibility of a controlled, voluntary rectal emptying of the "neorectum" by the patient, thus leading to an improved QoL and "normalization" of the patient's social and professional life.

Taking into account that LARS will affect the majority of patients after rectal resection and almost everyone after "ultralow" rectal resection, including coloanal anastomosis, our study group decided to evaluate the effect of a prophylactic application in patients before closure of their protective ostomy following LARS.

coloproctology 2017·39:341-343 https://doi.org/10.1007/s00053-017-0193-9

(c) Springer Medizin Verlag GmbH 2017

H. Rosen · J. Hebenstreit · G. Möslein · W. Kneist · G. Liebig-Hörl · A. Fürst

Prophylactic transanal irrigation for low anterior resection syndrome following rectal resection. Study protocol of a randomized controlled multicenter trial

\section{Abstract}

Defecation disorders and incontinence are common following low anterior resection of the rectum. Transanal irrigation (TAI) has been reported to be a cheap and effective treatment for improving the quality of life (QoL) of patients suffering from low anterior resection syndrome (LARS). Based on these observations, as well as on the fact that the majority of patients undergoing anterior resection are affected significantly after closure of their protective ostomies, a prophylactic application of TAI was considered in order to prevent a deterioration of QoL. To this end, a multicenter randomized controlled trial is planned that will evaluate the effect of TAI on (a) the number of defecation episodes, (b) LARS score, and (c) results of the 36-Item Short Form Health Survey (SF-36) in comparison with a control group who will receive the conventional supportive management following anterior resection.

\section{Keywords}

Colorectal surgery $\cdot$ Low anterior resection syndrome · Quality of life · Transanal irrigation · Randomized controlled trial

\section{Prophylaktische transanale Irrigation bei anteriorem Resektionssyndrom nach Rektumresektion. Studienprotokoll einer randomisierten kontrollierten Multizenterstudie}

\section{Zusammenfassung}

Stuhlentleerungsstörungen und Inkontinenz treten häufig nach tiefer anteriorer Rektumresektion auf. Die transanale Irrigation (TAI) gilt als preisgünstige und wirksame Behandlung zur Verbesserung der Lebensqualität („quality of life", QoL) von Patienten mit anteriorem Resektionssyndrom ("low anterior resection syndrome", LARS). Auf der Grundlage dieser Beobachtungen und angesichts der Tatsache, dass die Mehrheit der Patienten mit anteriorer Resektion nach Verschluss ihrer protektiven Ostomien deutlich beeinträchtigt sind, wurde eine prophylaktische Anwendung der TAl in Erwägung gezogen, um eine Verschlechterung der QoL zu vermeiden.
Zu diesem Zweck ist eine randomisierte kontrollierte Multizenterstudie geplant, in der die Wirkung der TAI auf (a) die Stuhlfrequenz, (b) den LARS-Score und (c) die Ergebnisse im 36-Item Short Form Health Survey (SF36) untersucht wird - im Vergleich zu einer Kontrollgruppe mit der herkömmlichen supportiven Therapie nach anteriorer Resektion.

\section{Schlüsselwörter}

Kolorektalchirurgie · Anteriores Resektionssyndrom · Lebensqualität · Transanale Irrigation - Randomisierte kontrollierte Studie

\section{Study design}

\section{Inclusion criteria}

a. Patients with rectal resection and an anastomosis below $5 \mathrm{~cm}$ ab ano (+/- colonic pouch) and a protective ileostomy

b. Proof of an uncomplicated healing of the anastomosis by endoscopy and/or radiology (enema), which will allow closure of the protective stoma as well as introduction of the irrigating device c. Informed consent

d. Physical and mental capability of the patient to understand and perform TAI independently

\section{Primary endpoint}

The primary endpoint is reduction in defecation episodes both diurnal and nocturnal by TAI every $24 \mathrm{~h}$ following closure of the protective stoma. 


\section{Secondary endpoints}

Secondary endpoints include evaluation of the effect of TAI on QoL by use of the LARS score [9] as well as the SF36 questionnaire at 1 week, 1 month, and 3 months following stoma closure.

Following this, further management of the patients is decided by each participating center, e.g., introduction of TAI for patients primarily randomized to the control arm, termination of TAI or reduction of the irrigation volume for patients in the "TAI group". However, the patients' number of defecation episodes, LARS score, and SF-36 results will be documented during the individual follow-up.

\section{Transanal irrigation}

Following fulfilment of the inclusion criteria, patients will be randomly allocated either to a TAI or a control group that will receive best conservative (supportive) therapy. Presence or absence of a colonic pouch will be used as a stratification criterion during the randomization process.

Patients randomized to the TAI group will be instructed by a dedicated (stoma) therapist/nurse on how to use the irrigation system before they undergo stoma closure. This should guarantee that patients will already have sufficient experience in using TAI when their bowel function starts after stoma closure.

After the beginning of bowel movement, TAI will be started using $1000 \mathrm{ml}$ of tap water every $24 \mathrm{~h}$ at a time point that can be chosen individually by the patients.

Based on previously reported experiences [10], TAI will be performed with the Peristeen ${ }^{\circledR}$ system (Coloplast A/S, Humblebaek, Denmark); however, in patients with difficulties in introducing the irrigator due to stenosis of the anastomosis, application of a large (28 French) Foley catheter will be accepted, which can be flushed by using 100-ml syringes.

\section{Statistical analysis}

\section{Sample size}

In a joint Austrian-Swiss study the authors were able to reduce the median number of defecation episodes in patients suffering from LARS from a median number of eight episodes per day to one per day, as well as from three per night to no episodes by application of TAI every $24 \mathrm{~h}$.

Based on these observations and calculating a minimal power of 0.80 and a significance level of 0.05 in a two-sided hypothesis, a sample size of 15 patients per group was regarded as the acceptable sample size for this trial.

\section{Summary}

Defecation disorders and incontinence are common following low anterior resection of the rectum, and transanal irrigation (TAI) has been reported to be a cheap and effective treatment to improve QoL of patients suffering from LARS. Based on these observations as well as on the fact that the majority of all patients following anterior resection will be affected significantly in the immediate period following closure of their protective ostomies, a prophylactic application of TAI to prevent deterioration of QoL was discussed. Therefore, a multicenter randomized controlled trial was planned to evaluate the effect of TAI on the number of defecation episodes, LARS score, and SF-36 questionnaire results compared with a control group who will receive the conventional supportive management following anterior resection.

\section{Corresponding address}

Univ. Prof. Dr. H. Rosen

Chair "Surgical Oncology", Sigmund Freud Medical School

Freud Platz 1, 1020 Vienna, Austria rosensurg@csi.com

\section{Compliance with ethical guidelines}

Conflict of interest. H. Rosen, J. Hebenstreit, G. Möslein, W. Kneist, G. Liebig-Hörl, and A. Fürst declare that they have no competing interests.

This article does not contain any studies with human participants or animals performed by any of the authors.

\section{References}

1. Bryant CL, Luniss PJ, Knowles CH et al (2012) Anterior resection syndrome. Lancet Oncol 13:403-408

2. Kakodkar R, Gupta S, Nundy S (2006) Low anterior resection with total mesorectal excision for rectal cancer:functionalassessmentand factorsaffecting outcome. Colorectal Dis 8:650-656

3. Hughes DL, Cornish J, Morris C, LARRIS Trial Management Group (2017) Functional outcome following rectal surgery-predisposing factors for low anterior resectionsyndrome. Int J Colorectal Dis. https://doi.org/10.1007/s00384017-2765-0

4. Chen TY, Wiltink LM, Nout RA et al (2015) Bowel function 14 years after preoperative shourt-course radiotherapy and total mesorectal excision for rectal cancer: report of a multicentre randomized trial. Clin Colorectal Cancer 14:106-114

5. Sturiale A, Martellucci J, Zurli L et al (2016) Longterm functional follow-up after anterior rectal resection for cancer. Int J Colorectal Dis. https:// doi.org/10.1007/s00384-016-2659-6

6. Lee WY, Takahashi T, Pappas T et al (2008) Surgical autonomic denervation results in altered colonic motility: an explanation for low anterior resection syndrome? Surgery 143:778-783

7. Fazio VW, Zutshi M, Remzi FH et al (2007) A randomized multicenter trial to compare longterm functional outcome, quality of life, and complications of surgical procedures for low rectal cancers. Ann Surg 246(7):481-490

8. Auwerda JJ, Bac DJ, Schouten WR (2001) Circadian rhythm of rectal motor complexes. Dis Colon Rectum 44:1328-1332

9. Emmertsen KJ, Laurberg S (2012) Low anterior resection syndrome score: development and validation of a symptom-based scoring system for bowel dysfunction after low anterior resection for rectal cancer. Ann Surg 255:922-928

10. Rosen H, Robert J, Tentschert G et al (2011) Transanal irrigation improves quality of life in patients with low anterior resection syndrome. Colorectal Dis 13:335-338

11. Koch SMP, Rietveld MP, Govaert B et al (2009) Retrograde colonic irrigation for faecal incontinence after low anterior resection. Int J Colorectal Dis 24:1019-1022

12. Mege D, Meurette G, Vitton V et al (2017) Sacral nerve stimulation can alleviate symptoms of bowel dysfunction after colorectal resections. Colorectal Dis. https://doi.org/10.1111/codi.13624

13. Iwama T, Imajo M, Yaegashi K et al (1989) Self washout method for defecational complaints following low anterior resection. Jpn J Surg 19:251-253

14. Martellucci J (2016) Anterior resection syndrome: A treatment algorithm. Dis Colon Rectum 59:79-82 